\title{
A comparative study on endovascular treatment of (sub)acute critical limb ischemia: mechanical thrombectomy vs thrombolysis
}

This article was published in the following Dove Press journal:

Drug Design, Development and Therapy

I8 April 2017

Number of times this article has been viewed

\author{
Mariya Kronlage ${ }^{1,2}$ \\ Ilka Printz' \\ Britta Vogel' \\ Erwin Blessing 3 \\ Oliver J Müller ${ }^{1,2}$ \\ Hugo A Katus ${ }^{1,2}$ \\ Christian Erbel'
}

'Department of Cardiology, Angiology and Pneumology, University Hospital Heidelberg, ${ }^{2}$ DZHK German Center for Cardiovascular Research, Partner Site Heidelberg/Mannheim, Heidelberg, ${ }^{3} \mathrm{SRH}$ Klinikum Karlsbad Langensteinbach, Karlsbad, Germany
Correspondence: Mariya Kronlage Department of Cardiology, Angiology and Pneumology, University Hospital Heidelberg, Im Neuenheimer Feld 4I0, 69120 Heidelberg, Germany

Tel +49 I76 29533989

Email mariya.kronlage@med.uniheidelberg.de
Objective: The aim of this study was to compare different interventional methods for treatment of (sub)acute limb ischemia upon thrombotic occlusions of the lower extremity in terms of their safety and efficacy in a tertiary hospital setting.

Design: This is a retrospective, single-center study of non-randomized data.

Methods: A total of 202 patients, including 26 critically ill patients, underwent rotational thrombectomy $\left(\operatorname{Rotarex}^{\circledR}\right)$, local thrombolysis (recombinant tissue plasminogen activator), or combination of both at the University Hospital Heidelberg (2006-2015). The different interventional procedures were compared in terms of overall and amputation-free survival, as well as patency in a 1-year follow-up (Kaplan-Meier analysis).

Results: The study demonstrated a primary revascularization success of $>98 \%$ in all groups. One year after revascularization, primary and secondary patency after mechanical thrombectomy alone were significantly better in comparison to local thrombolysis or a combination of Rotarex ${ }^{\mathbb{R}}$ and lysis $(63 \%$ and $85 \%, P<0.05)$. Overall survival 12 months after intervention reached up to $96 \%$ in noncritically ill patients, and amputation-free survival was $94.3 \%$ in all three groups. Mean hospitalization duration and rate of major bleedings were significantly increased after thrombolysis compared to $\operatorname{Rotarex}^{\circledR}(P<0.05)$.

Conclusion: In patients with (sub)acute limb ischemia, Rotarex ${ }^{\circledR}$ mechanical thrombectomy represents a safe and effective alternative to thrombolysis and is associated with a reduced rate of major bleedings, shorter hospitalization durations, and lower costs.

Keywords: acute limb ischemia, thrombolysis, mechanical thrombectomy, Rotarex ${ }^{\circledR}$, arterial thrombosis and embolism, acute artery occlusion

\section{Abbreviations}

ABI, ankle-brachial index; ALI, acute limb ischemia; CLI, critical limb ischemia; PTA, percutaneous transluminal angioplasty; rtPA, recombinant tissue plasminogen activator; SFA, superficial femoral artery.

\section{Introduction}

$\mathrm{ALI}^{1}$ is caused by a thrombotic and/or embolic occlusion of a peripheral vessel. ${ }^{1}$ Patients with ALI represent a high-risk cohort ${ }^{2}$ in need of complex revascularization procedures that are often associated with a significant rate of periinterventional complications.

The consequences of ALI such as prolonged hospitalization, major limb amputation, and/or death have a profound socioeconomic impact worldwide. Recently, it has been shown that in a 1-year follow-up, limb loss occurs in $10 \%-70 \%$ of all ALI cases, depending on the Rutherford categories. In addition, mortality following acute 
low-extremity ischemia reaches up to $15 \% ;^{1}$ unfortunately, these numbers have not improved over the years. ${ }^{3}$

Hence, development of new treatment options and better management of ALI is an urgent need in clinical everyday life. During the past decades, interventional treatment of acute CLI such as low-dose targeted streptokinase treatment has proven to be an attractive alternative to surgical procedures., ${ }^{4,5}$ Three different multicenter trials have compared thrombolysis with surgical treatment so far: the Rochester study, ${ }^{6}$ the STILE trial (Surgery versus Thrombolysis for Ischemic Lower Extremity) conducted in 1994, ${ }^{7}$ and the TOPAS (Thrombolysis Or Peripheral Arterial Surgery) trial conducted in $1996 .{ }^{8}$ Based on their convincing results, catheter-based thrombolysis emerged as a first-line therapy of ALI and is preferred to surgery unless there are absolute thrombolysis contraindications. ${ }^{4}$

Meanwhile, additional treatment options such as different percutaneous mechanical thrombectomy devices have emerged. ${ }^{9,10}$ A very frequently used treatment option that has gained popularity in interventional practice is the Rotare ${ }^{\circledR}$ device (Straub Medical AG, Straubstrasse, Switzerland) that combines thrombus fragmentation and suction, and thus minimizes the hazard of peripheral embolizations.

Despite the high variety of different techniques available on the market, a systematical evaluation of the advantages and disadvantages of mechanical thrombectomy compared to classical thrombolysis therapy is still lacking. The current study aimed to compare safety and efficacy of mechanical thrombectomy, local thrombolysis treatment, and the combination of both during a 12-month follow-up based on a collective of 202 patients from the Heidelberg registry for peripheral artery disease.

\section{Patients and methods Study design}

The current investigation is a non-randomized, retrospective single-center study. A total of 202 patients with acute and subacute thrombotic occlusions of the lower extremity, followed by a CLI, were enrolled between 2006 and 2015 at the Department of Cardiology, Angiology and Pneumology, University Hospital Heidelberg. Follow-up examinations (clinical visit, ABI, color duplex sonography) were performed immediately after, as well as 1 , 3, 6, and 12 months after intervention. The study was approved by the local ethics committee at the University Hospital Heidelberg as a part of the Heidelberg registry for peripheral artery disease (S-331/2013). Informed consent was waived by the local ethics committee due to the retrospective design of the study, and provided that only the attending physicians were allowed to assess nonanonymized patient data.

The registry data were collected in accordance with the Declaration of Helsinki.

\section{Interventional treatment methods}

All patients received a bolus of $2.500 \mathrm{U}$ of heparin after placement of a $6 \mathrm{~F}$ sheath introducer in the femoral artery. During intervention, all patients additionally received heparin to reach an activated clotting time of 250 seconds. If balloon dilatation and/or stent implantation was indicated, patients received $500 \mathrm{mg}$ aspirin during and $300 \mathrm{mg}$ clopidogrel after the intervention.

Out of 202 patients, 146 received primary treatment with the Rotare ${ }^{\circledR}$ device, 28 underwent thrombolysis, and 28 patients received a combination of Rotarex ${ }^{\circledR}+$ thrombolysis. The type of intervention was selected by the interventionalist after angiography of the occluded lower limb, depending on the extension of the occlusion and the availability of the Rotarex $^{\circledR}$ system.

For local thrombolysis, a bolus of $10 \mathrm{mg}$ rtPA was given after placing the local thrombolysis catheter (CraggMcNamara, Ev3 Endovascular Inc., Plymouth, MN, USA) inside the thrombotic occlusion. Periinterventionally, rtPA was continuously administered (rate: $1 \mathrm{mg} / \mathrm{h}$ ) for 18 hours in addition to heparin (target partial thromboplastin time of 60-80 seconds).

For rotational thrombectomy, an angiogram was performed, beginning at the proximal part of the common iliac artery and continuing down to the feet arteries. After placing the Rotare ${ }^{\circledR}$ wire through the thrombotic occlusion, the rotational thrombectomy device was slowly advanced and retracted in order to avoid embolic complications downstream of the occlusion. If necessary, the procedure was repeated until the blood flow was fully restored.

If indicated, a PTA and stent implantation was performed upon thrombus removal.

\section{Statistical analysis}

Chi-square tests were used to compare categorical data. Continuous variables were represented as mean \pm standard deviation. Analysis of variance was used to compare means when variables were normally distributed. Kaplan-Meier curves were drawn to present survival data, and log-rank tests were used to assess differences in time-to-event end points. A nonparametric (Kruskal-Wallis) test was used to compare the mean duration of hospital stay between the different groups. $P$-values of $<0.05$ were considered statistically significant. Since no adjustment for multiplicity 
was performed, all $P$-values need to be interpreted descriptively, and in case of missing data, a complete-case analysis was performed. Data analysis was executed using GraphPad (Version 6.0) and SPSS (Version 22.0) software.

\section{Results}

\section{Complex lesion morphology and patient characteristics in a tertiary hospital collective}

A total of 202 consecutive patients underwent a revascularization procedure upon thrombotic occlusion of the peripheral arteries between 2006 and 2015 at the University Hospital Heidelberg. Twenty-six out of 202 patients included in the study were critically ill with the following leading diagnoses: severe sepsis $(n=7)$, acute cardiac failure $(n=5)$, acute coronary syndrome $(n=7)$, pulmonary embolism $(n=3)$, acute-on-chronic renal failure $(n=3)$, or stroke $(n=1)$. Mean age in the Rotarex ${ }^{\circledR}$-, thrombolysis-, and Rotarex ${ }^{\circledR}$ plus thrombolysis-treated group was $67.5 \pm 11.4,61.5 \pm 14.3$, and $72.5 \pm 9.7$ years, respectively. Demographic data regarding the patients' collective as well as relevant cardiovascular comorbidities are summarized in Tables 1 and 2. Duration of symptoms prior to hospitalization was less than 2 weeks in $34 \%$ of the Rotarex ${ }^{\circledR}, 54 \%$ of the thrombolysis, and $46 \%$ of the Rotarex ${ }^{\circledR}$ plus thrombolysis group.

Target lesion characterization was performed by two independent examiners based on major angiographic features: calcification, degree of thrombotic occlusion, as well as length of occlusion. Low calcification grade was defined as no or only isolated plaques as previously described; ${ }^{11}$ up to $50 \%$ calcification was defined as moderate, and $>50 \%$ was referred to as severe.

The majority of patients displayed severe thrombotic burden: 67\% (Rotarex ${ }^{\circledR}$ group), 71\% (thrombolysis group),

Table I Demographic characteristics of the study population in terms of age, gender, and weight

\begin{tabular}{|c|c|c|c|c|}
\hline & $\begin{array}{l}\text { Rotarex }^{\circledR} \\
\text { (Straub } \\
\text { Medical AG, } \\
\text { Straubstrasse, } \\
\text { Switzerland) }\end{array}$ & Lysis & Rotare $^{\circledR}+$ lysis & $P$-value \\
\hline Age (years) & $67.5 \pm 11.4$ & $61.5 \pm 14.3$ & $72.5 \pm 9.7$ & $\begin{array}{l}\mathrm{R} \text { vs } \mathrm{R}+\mathrm{L}^{*} \\
\mathrm{R} \text { vs } \mathrm{L} \text { ns } \\
\mathrm{L} \text { vs } \mathrm{R}+\mathrm{L}^{* * *}\end{array}$ \\
\hline Gender & $\begin{array}{l}\text { M 63.I\% } \\
\text { F 36.9\% }\end{array}$ & $\begin{array}{l}\text { M 64.3\% } \\
\text { F 35.7\% }\end{array}$ & $\begin{array}{l}\text { M } 71.4 \% \\
\text { F } 29.4 \%\end{array}$ & $\begin{array}{l}\mathrm{R} \text { vs } \mathrm{R}+\mathrm{L}^{* *} \\
\mathrm{R} \text { vs } \mathrm{L} n \mathrm{~ns} \\
\mathrm{~L} \text { vs } \mathrm{R}+\mathrm{L}^{* *}\end{array}$ \\
\hline Weight (kg) & $74.4 \pm \mid 4.1$ & $76.2 \pm 14$ & $80.7 \pm 10.9$ & ns \\
\hline
\end{tabular}

Notes: $* P<0.05, * * P<0.01$, and $* * * P<0.001$.

Abbreviations: M, male; F, female; R, Rotarex ${ }^{\oplus}$; L, lysis; ns, nonsignificant. and $89 \%$ (Rotarex $^{\circledR}$ plus thrombolysis group). In contrast, the grade of lesion calcification was low, whereas the vast majority of thrombotic occlusions treated in the study extended over a length of more than $10 \mathrm{~cm}$ in all three groups $(P>0.05$, Table 3$)$.

The described interventions took place predominantly on native vessels (Rotarex ${ }^{\circledR}: 68.5 \%$, thrombolysis: $78.6 \%$, and Rotare ${ }^{\circledR}+$ thrombolysis: $71.4 \%$ ). In addition to thrombectomy and/or thrombolysis, the rate of additional PTA did not differ between the three interventional groups $(P>0.05$, Table 3). No difference was seen for the number of stent implantations after thrombectomy and/or thrombolysis between the groups either (Table 3). The exact target lesion localizations are represented in Table 4 which shows significantly more interventions in the SFA in the Rotarex ${ }^{\circledR}$ vs thrombolysis group $(P<0.01)$.

\section{Safety and efficacy of interventional treatment in the prevention of major end points}

For evaluation of overall survival, patients were additionally subdivided into two groups: critically ill in-hospital patients (26 out of 202) where limb ischemia occurred as a complication of a primary systemic disease, and noncritically ill patients (176 out of 202) who had been admitted with the leading symptom of lower-extremity ALI. Kaplan-Meier analysis was performed in order to trace overall and amputation-free survival during a 1 year follow-up (Figure 1A-D). Overall survival 12 months after intervention was $96.02 \%$ in noncritically ill and $65 \%$ in critically ill patients. A total of 16 patients died during the follow-up due to septic shock $(n=5)$, cardiogenic shock $(n=4)$, asystole $(n=1)$, electromechanical decoupling $(n=1)$, major stroke $(n=1)$, and cancer $(n=1)$; in three patients, no information regarding the specific cause of death was available. Revascularization failure leading to amputation occurred in only three $(1.5 \%)$ out of 202 patients. More specifically, one patient had a severe bleeding from the puncture site leading to surgical hematoma removal. Due to interruption of anticoagulation during the surgery, a subsequent total bypass re-occlusion occurred and a major amputation had to be performed. The second patient developed a fulminant phlegmone and was referred to surgery for urgent wound debridement resulting in a limb loss. The third patient refused a second intervention, although a major thrombotic residue upon primary thrombolysis was diagnosed.

By further evaluating the complication rate between the groups, our study demonstrated that Rotarex ${ }^{\circledR}$-treated patients showed a significantly lower rate of major bleeding 
Table 2 Major comorbidities of the study population

\begin{tabular}{llll}
\hline & Rotarex $^{\circledR}$ & Lysis & Rotarex $^{\circledR}+$ lysis \\
\hline Ischemic cardiac disease & $44.5 \%(65 / / 46)$ & $39.3 \%(I I / 28)$ & $46.4 \%(I 3 / 28)$ \\
Arterial hypertension & $75.3 \%(I I 0 / I 46)$ & $78.6 \%(22 / 28)$ & $78.6 \%(22 / 28)$ \\
Diabetes mellitus & $32.2 \%(47 / / 46)$ & $28.6 \%(8 / 28)$ & $50 \%(I 4 / 28)$ \\
Smoking & $63.7 \%(93 / / 46)$ & $60.7 \%(I 7 / 28)$ & $67.9 \%(I 9 / 28)$ \\
Kidney failure (III-V) & Stadium III I7.8\% (26/I46) & Stadium III 2I.4\% (6/28) & Stadium III I0.7\% (3/28) \\
& Stadium IV 3.4\% (5/I46) & Stadium IV 3.6\% (I/28) & Stadium IV I0.7\% (3/28) \\
Hyperlipidemia & Stadium V 2.1\% (3/I46) & Stadium V 0 & Stadium V 0 \\
\hline
\end{tabular}

Note: $P$-values $>0.05$

vs thrombolysis-treated ones ((non)critically ill, $P<0.05$, Table 5). Out of all patients with a relevant bleeding, a surgical hematoma removal was necessary only once; no bleeding-related death events were observed. Local vascular complications, such as pseudoaneurysm and/or arteriovenous fistula, occurred in one case each (Table 5), and one patient in the Rotarex ${ }^{\circledR}$ plus thrombolysis group developed a compartment syndrome that required further surgical treatment. The mean duration of hospital stay in the Rotarex ${ }^{\circledR}$ group was significantly reduced in comparison to the two other groups of noncritically ill patients $(P<0.001$, Table 5$)$.

\section{High primary revascularization rates associated with interventional treatment of $A L I$}

Primary revascularization success immediately upon procedure was observed in the vast majority of all cases: $>98 \%$. In terms of primary patency, the study showed that the Rotare ${ }^{\circledR}$-treated group was significantly better than both the thrombolysis and Rotare ${ }^{\circledR}$ plus thrombolysis group
$(P<0.0001)$. In line with this was also the secondary patency rate upon mechanical thrombectomy $(85 \%)$ showing less re-interventions compared both to thrombolysis and to combined therapy 12 months after primary revascularization $(P<0.05$, Figure 2A and B). Examples of typical lesions treated with Rotare ${ }^{\circledR}$ are shown in Figures S1 and S2.

Another important issue to address is whether differences in the duration of symptoms might have an impact on patients' outcome. The study demonstrated that the assessment of patients with acute ( $<2$ weeks) vs subacute (2-4 weeks) presentation of symptoms did not reveal any significant differences in terms of patency and/or amputationfree survival (data not shown).

\section{Substantial $A B I$ improvement upon intervention in all groups}

Prior to intervention, all three patient groups presented severely reduced ABI values: $0.36 \pm 0.28$. Immediately after intervention, the $\mathrm{ABI}$ values improved markedly in all three groups $\left(\operatorname{Rotarex}^{\circledR} 0.87 \pm 0.23\right.$, Rotare $^{\circledR}+$ thrombolysis $^{\circ}$

Table 3 Major lesions' characteristics and their distribution in different interventional groups

\begin{tabular}{|c|c|c|c|c|}
\hline & Rotarex $^{\circledR}$ & Lysis & Rotarex $^{\circledR}+$ lysis & $P$-value \\
\hline Native vessel & $68.5 \%(100 / 146)$ & $78.6 \%(22 / 28)$ & $71.4 \%(20 / 28)$ & ns \\
\hline \multirow[t]{3}{*}{ Bypass } & I.4\% (2/I46) & $3.6 \%(1 / 28)$ & $10.7 \%(3 / 28)$ & $\mathrm{R}$ vs $\mathrm{R}+\mathrm{L}^{*}$ \\
\hline & & & & $R$ vs $L$ ns \\
\hline & & & & $\mathrm{L}$ vs $\mathrm{R}+\mathrm{L}$ ns \\
\hline \multicolumn{5}{|l|}{ Calcification grade } \\
\hline Low & $70.6 \%(103 / 146)$ & $78.6 \%(22 / 28)$ & $71.4 \%(20 / 28)$ & ns \\
\hline Moderate-severe & $29.5 \%(43 / / 46)$ & $21.4 \%(6 / 28)$ & $28.6 \%(8 / 28)$ & ns \\
\hline \multicolumn{5}{|l|}{ Thrombotic burden } \\
\hline Low & $32.3 \%(50 / / 46)$ & $28.6 \%(8 / 28)$ & $10.7 \%(3 / 28)$ & $\mathrm{R}$ vs $\mathrm{R}+\mathrm{L}^{*}$ \\
\hline \multirow[t]{2}{*}{ Moderate-severe } & $65.8 \%(96 / 146)$ & $71.7 \%(20 / 28)$ & $89.3 \%(25 / 28)$ & $R$ vs $L$ ns \\
\hline & & & & $\mathrm{L}$ vs $\mathrm{R}+\mathrm{L}$ ns \\
\hline \multicolumn{5}{|c|}{ Length of occlusion $(\mathrm{cm})$} \\
\hline$>10$ & $75.3 \%(110 / 146)$ & $71.4 \%(20 / 28)$ & $85.7 \%(24 / 28)$ & ns \\
\hline$<10$ & $24.7 \%(36 / 146)$ & $28.6 \%(8 / 28)$ & $14.3 \%(4 / 28)$ & ns \\
\hline Stent & $55.5 \%(80 / / 46)$ & $46.4 \%(13 / 28)$ & $42.9 \%(12 / 28)$ & ns \\
\hline PTA & $73.9 \%(108 / 146)$ & $71.4 \%(20 / 28)$ & $78.6 \%(22 / 28)$ & ns \\
\hline
\end{tabular}

Note: $* P<0.05$.

Abbreviations: ns, nonsignificant; R, Rotarex ${ }^{\circledast}$; L, lysis; PTA, percutaneous transluminal angioplasty. 
Table 4 Target lesion localization for Rotarex ${ }^{\circledR}$, lysis, and Rotarex ${ }^{\circledR}+$ lysis

\begin{tabular}{lllll}
\hline & Rotarex $^{\circledR}$ & Lysis & Rotarex $^{\circledR}+$ lysis & P-value \\
\hline Iliac vessels & $12.5 \%$ & $28.6 \%$ & $16.7 \%$ & ns \\
SFA & $69.3 \%$ & $40 \%$ & $52 \%$ & R vs R+L ns \\
& & & & $\begin{array}{l}\text { R vs L** } \\
\text { B vs R+L ns }\end{array}$ \\
Below the knee & $18.7 \%$ & $31.4 \%$ & $31.3 \%$ & ns \\
\hline
\end{tabular}

Note: $* * p<0.01$.

Abbreviations: ns, nonsignificant; R, Rotarex ${ }^{\circledR}$; L, lysis; SFA, superficial femoral artery.

$0.88 \pm 0.28$, thrombolysis $0.71 \pm 0.31, P>0.05)$ and remained stable over the next 12 months (Figure 3 and Table S1).

\section{Discussion}

Epidemiological studies based on large populations show that ALI is a severe diagnosis and an independent predictor of both major amputation and mortality. ${ }^{2}$ Interventional methods for ALI treatment have been undergoing significant technical development over the last years. The Straub-Rotarex ${ }^{\mathbb{R}}$ catheter has been widely used as a common alternative to local thrombolysis for more than a decade now, ${ }^{12}$ and different trials have pointed out the strengths of a catheter-guided rotational thrombectomy so far. ${ }^{13-16}$ To the best of our knowledge, this is the first trial comparing Rotare ${ }^{\circledR}$ mechanical thrombectomy with the classical thrombolysis therapy, and the combination of both, in patients with ALI.

A
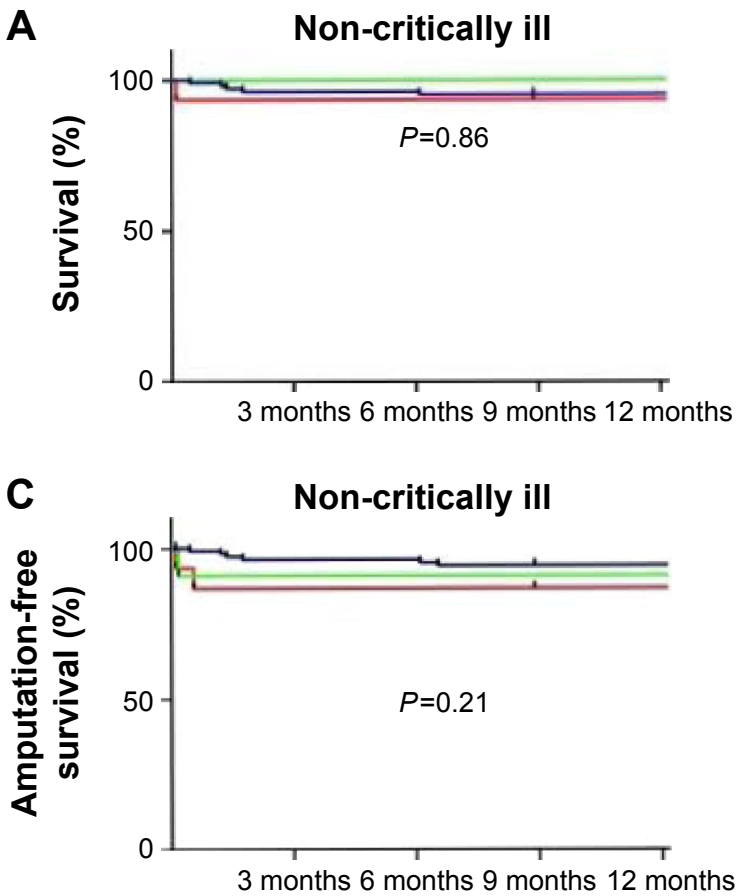

Previously published data of a single-arm study by Zeller et al demonstrated excellent primary revascularization success rates $(92 \%)$ over a period of 12 months upon Rotare ${ }^{\circledR}$ treatment in a cohort of 98 ALI patients. ${ }^{12}$ However, this study also revealed a significant restenosis rate of up to $33 \%$ in native vessels, $74 \%$ in in-stent re-stenosis, and $86 \%$ in bypass graft occlusions. ${ }^{12}$ Three percent of all patients underwent amputation, and one patient died during follow-up. Wissgott et al investigated (sub)acute bypass occlusions in 20 patients and achieved complete thrombus removal in $90 \%$ of all cases ${ }^{17}$ using the Rotarex ${ }^{\circledR}$ device or thrombolysis. One patient needed a re-intervention, and one suffered a major bleeding due to introducer sheath dislocation, followed by operative hematoma removal; there were no death events reported. Another study in 2001 by Bérczi et al followed up on 18 patients treated with the Rotarex ${ }^{\circledR}$ thrombectomy device. ${ }^{18}$ The primary procedural success was $94 \%$; however, the authors reported a high complication rate of $31.5 \%$, including perforation and peripheral embolization. Primary and secondary patency 12 months after revascularization was $39 \%$ and $53 \%$, respectively; there were no amputations or death events. In our cohort, primary revascularization success was observed in the vast majority of all cases ( $>98 \%$ ), which was comparable to the results of previous trials. ${ }^{12,18,19}$ Generally, our collective of 202 patients was characterized by a substantial heterogeneity. Patients who are admitted to the hospital with the leading
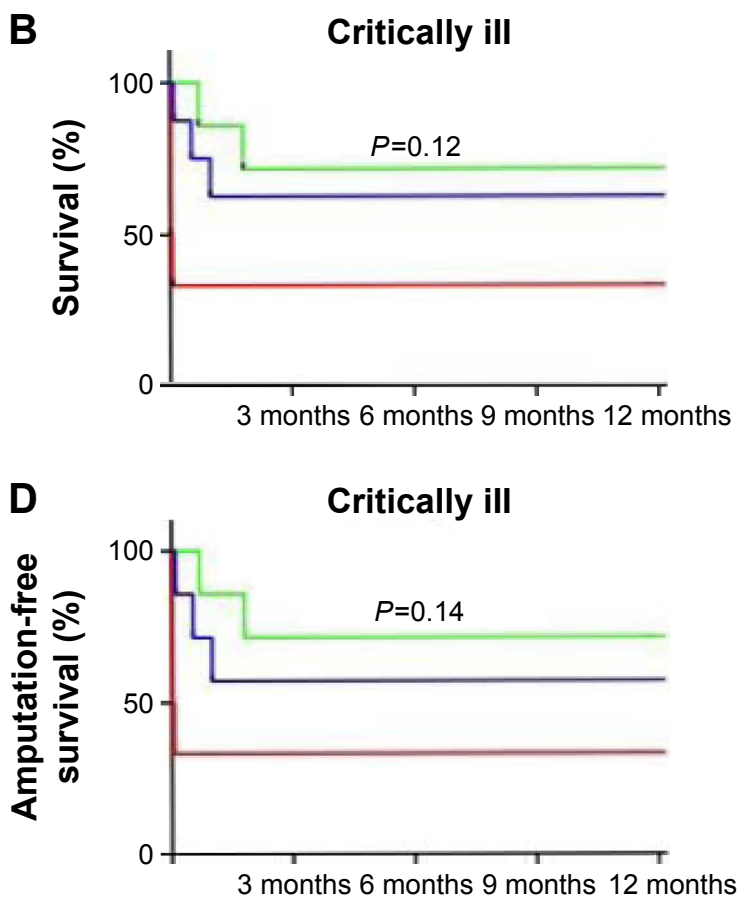

Figure I Kaplan-Meier curves representing overall survival (A and B) and amputation-free survival (C and D) of Rotarex ${ }^{\circledR}$ (blue)-, lysis (green)-, and Rotarex ${ }^{\circledR}+$ lysis (red)-treated patients. The figure is subdivided into a population of noncritically ill (left panel) vs critically ill (right panel) patients. P-values are attributed to the corresponding subfigures. 
Table 5 Major complications in the three intervention groups. Patients were additionally subdivided into critically ill (white space) and noncritically ill (gray space)

\begin{tabular}{|c|c|c|c|c|c|}
\hline & Rotarex $^{\circledR}$ & Lysis & Rotare $^{\circledR}+$ lysis & Total & $P$-value \\
\hline \multirow[t]{6}{*}{ Major bleeding } & $3.6 \%(5 / 138)$ & $22.2 \%(4 / 18)$ & 0 & $5.11 \%(9 / 176)$ & R vs $L^{*}$ \\
\hline & & & & & $R$ vs $R+L$ ns \\
\hline & & & & & L vs $R+L^{*}$ \\
\hline & 0 & $10 \%(1 / 10)$ & $25 \%(2 / 8)$ & II.5\% (3/26) & R vs L ns \\
\hline & & & & & $\mathrm{R}$ vs $\mathrm{R}+\mathrm{L} * *$ \\
\hline & & & & & $\mathrm{L}$ vs $\mathrm{R}+\mathrm{L}$ ns \\
\hline \multirow[t]{2}{*}{ Aneurysma sp. } & $2.9 \%(4 / 138)$ & 0 & 0 & $2.3 \%(4 / 176)$ & ns \\
\hline & 0 & 0 & $12.5 \%(1 / 8)^{*}$ & $3.8 \%(I / 26)$ & ns \\
\hline \multirow[t]{2}{*}{ AV-fistula } & $0.7 \%(1 / 138)$ & 0 & 0 & $0.6 \%(1 / 176)$ & ns \\
\hline & 0 & 0 & 0 & 0 & ns \\
\hline \multirow[t]{4}{*}{ Compartment } & 0 & 0 & 0 & 0 & ns \\
\hline & 0 & 0 & $12.5 \%(1 / 8)$ & $3.8 \%(1 / 26)$ & $R$ vs $L$ ns \\
\hline & & & & & $\mathrm{R}$ vs $\mathrm{R}+\mathrm{L}^{*}$ \\
\hline & & & & & L vs $\mathrm{R}+\mathrm{L}^{*}$ \\
\hline \multirow[t]{4}{*}{ Hospital length stay (days) } & $1.4 \pm 0.9$ & $4.6 \pm 3$ & $4.4 \pm 1.8$ & - & R vs L*** \\
\hline & & & & & $R$ vs $R+L^{* * *}$ \\
\hline & & & & & $\mathrm{L}$ vs $\mathrm{R}+\mathrm{L}$ ns \\
\hline & $21.7 \pm 34.4$ & $13.3 \pm 4.5$ & $18.3 \pm 9.36$ & - & ns \\
\hline
\end{tabular}

Notes: $* P<0.05, * * P<0.01$, and $* * * P<0.001$. Data are presented as mean \pm standard deviation or $\%(n / N)$.

Abbreviations: R, Rotarex ${ }^{\oplus}$; L, lysis; ns, nonsignificant; AV, arteriovenous.

and often single diagnosis of ALI (defined as noncritically ill) have a different starting point, a better perspective, and often a better outcome than critically ill patients, where ALI usually occurs in the context of multiple-organ failure, disseminated intravasal coagulopathy, severe sepsis, and/ or shock. The differentiation between critically ill and noncritically ill patients in our study helps to illustrate that most of the periinterventional complications (eg, prolonged bleedings, amputation, and/or death) take place in the group of critically ill patients; this needs to be addressed and taken into consideration when assessing the general outcome after such an intervention. Indeed, major complications occurred in 19 cases during a follow-up of 12 months: a total of three amputations and 16 death cases, predominantly in critically ill patients.

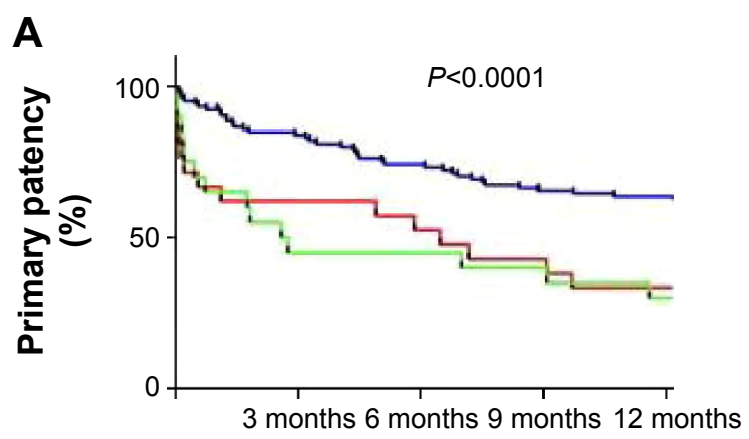

However, the overall results of our trial remain unchanged despite the substantial number of critically ill patients enrolled in comparison to existing studies. In contrast, Zeller et al ${ }^{12}$ reported cardiogenic shock in one patient, Wissgott et a ${ }^{17}$ excluded patients with more advanced lesions (acute ischemia in stage III) or multiple lesions in their study, and Stanek et $\mathrm{al}^{20}$ reported about 40 patients with the leading diagnosis of peripheral arterial thromboembolic occlusions who were admitted selectively for revascularization. Thus, despite the high proportion (13\%) of critically ill patients enrolled, and the high thrombotic burden in most cases, periinterventional success remains comparable to the results of previous trials.

Direct comparison between different interventional techniques in the current study demonstrated that the rate of major

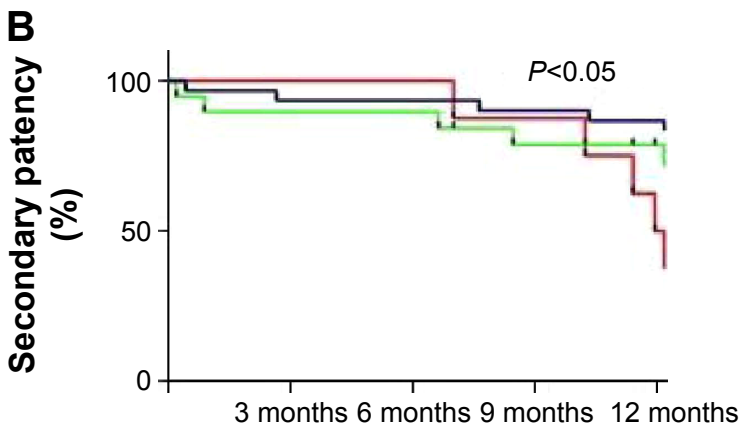

Figure 2 Twelve-month freedom from target lesion revascularization, re-occlusion, or significant restenosis is presented as Kaplan-Meier primary (A) and secondary patency (B) curves. Rotarex ${ }^{\circledR}$-treated patients are coded in blue, lysis-treated in green, and Rotarex ${ }^{\circledR}+$ lysis-treated in red. $P$-values are attributed to the corresponding subfigures. 


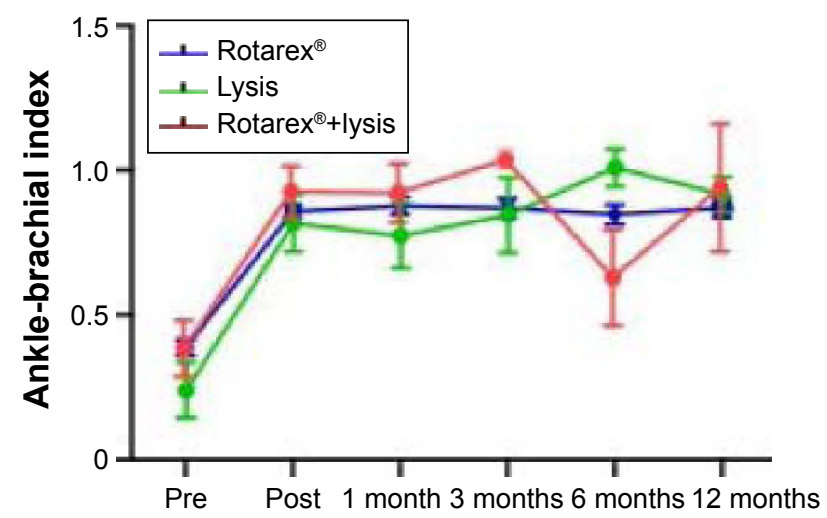

Figure $3 \mathrm{ABI}$ prior to (pre), immediately after (post), as well as I, 3, 6, and 12 months after revascularization. Rotarex ${ }^{\circledR}$-treated patients are identified in blue, lysis-treated patients in green, and Rotarex ${ }^{\circledast}+$ lysis-treated ones in red. Abbreviation: $A B I$, ankle-brachial index.

bleedings was significantly lower in Rotare ${ }^{\circledR}$-treated patients than in those receiving thrombolysis. Moreover, duration of hospitalization was also significantly prolonged in noncritically ill patients who underwent local thrombolysis therapy, also bearing more procedure-related costs. Thus, mechanical thrombectomy by Rotare ${ }^{\circledR}$ vs other treatment options provides advantages in terms of safety, shorter duration of hospitalizations, and lower costs.

In addition, mechanical thrombectomy was associated with a better outcome in terms of primary $(>63 \%)$ and secondary patency $(>85 \%)$ than thrombolysis alone and a combination of both. However, this result needs to be set into perspective against the predominant type of target lesions in the three treatment groups.

We cannot rule out lesion localization as a confounder, since the number of SFA revascularizations was highest in the Rotare ${ }^{\circledR}$ group and SFA lesions are generally more easily accessible than more distal occlusions in smaller arteries below the knee.

\section{Strengths and limitations}

As a retrospective analysis, the current study contains certain known limitations. In addition, the number of patients is limited, especially the group of critically ill patients, and thus, the results regarding the major end points need to be interpreted with caution.

\section{Conclusion}

The current study provides a first rationale comparison between frequently applied interventional methods for the treatment of (sub)acute lower-extremity ischemia. Rotare ${ }^{\circledR}$-mechanical thrombectomy was not inferior to local thrombolysis and was associated with a lower complication rate, shorter duration of hospitalizations, and lower costs in a 12-month follow-up in a tertiary hospital collective. Further prospective randomized controlled trials are necessary to evaluate the results of the study.

\section{Acknowledgments}

The authors are grateful to Dr Christian Stock (Institute for Medical Biometry and Informatics, University Hospital Heidelberg, Germany) for his statistical support and helpful manuscript suggestions. This work was supported by a grant from ab medica GmbH to E.B. for a Rotarex ${ }^{\circledR}$ evaluation study.

\section{Disclosure}

The authors report no conflicts of interest in this work.

\section{References}

1. Davies MG. Criticial limb ischemia: epidemiology. Methodist Debakey Cardiovasc J. 2012;8(4):10-14.

2. Baril DT, Patel VI, Judelson DR, et al; Vascular Study Group of New England. Outcomes of lower extremity bypass performed for acute limb ischemia. J Vasc Surg. 2013;58(4):949-956.

3. Norgren L, Hiatt WR, Dormandy JA, Nehler MR, Harris KA, Fowkes FGR; TASC II Working Group. Inter-society consensus for the management of peripheral arterial disease (TASC II). Eur J Vasc Endovasc Surg. 2007; 33 Suppl 1:S1-S75.

4. Morrison HL. Catheter-directed thrombolysis for acute limb ischemia. Semin Intervent Radiol. 2006;23(3):258-269.

5. Dotter CT, Rösch J, Seaman AJ. Selective clot lysis with low-dose streptokinase. Radiology. 1974;111(1):31-37.

6. Ouriel K, Shortell CK, DeWeese JA, et al. A comparison of thrombolytic therapy with operative revascularization in the initial treatment of acute peripheral arterial ischemia. J Vasc Surg. 1994;19(6):1021-1030.

7. Weaver FA, Comerota AJ, Youngblood M, Froehlich J, Hosking JD, Papanicolaou G. Surgical revascularization versus thrombolysis for nonembolic lower extremity native artery occlusions: results of a prospective randomized trial. The STILE Investigators. Surgery versus Thrombolysis for Ischemia of the Lower Extremity. J Vasc Surg. 1996;24(4):513-521; discussion 521-523.

8. Ouriel K, Veith FJ, Sasahara AA. Thrombolysis or peripheral arterial surgery: phase I results. TOPAS Investigators. J Vasc Surg. 1996;23(1): 64-73; discussion 74-75.

9. Swischuk JL, Fox PF, Young K, et al. Transcatheter intraarterial infusion of rt-PA for acute lower limb ischemia: results and complications. J Vasc Interv Radiol. 2001;12(4):423-430.

10. Lichtenberg M, Stahlhoff W, Boese D, Hailer B. Twelve months outcome after percutaneous mechanical thrombectomy for treatment of acute femoropopliteal bypass occlusion. Cardiovasc Interv Ther. 2013; 28(2):178-183.

11. Ohana M, El Ghannudi S, Girsowicz E, et al. Detailed cross-sectional study of 60 superficial femoral artery occlusions: morphological quantitative analysis can lead to a new classification. Cardiovasc Diagn Ther. 2014;4(2):71-79.

12. Zeller T, Frank U, Bürgelin K, et al. [Long-term results after recanalization of acute and subacute thrombotic occlusions of the infra-aortic arteries and bypass-grafts using a rotational thrombectomy device]. Rofo. 2002;174(12):1559-1565. German [with English abstract].

13. Zeller T, Müller C, Frank U, Bürgelin KH, Horn B, Roskamm H. [The Straub-Rotarex thrombectomy system: initial experiences]. Rofo. 2001;173(7):626-631. German [with English abstract]. 
14. Wissgott C, Kamusella P, Andresen R. Treatment of femoropopliteal stenoses and occlusions with mechanical rotational catheters: comparison of results with the Rotarex and Pathway devices. J Cardiovasc Surg (Torino). 2012;53(2):177-186.

15. Wissgott C, Andresen R. [Comments: interventional revascularisation of acute and subacute occlusions with the Rotarex device]. Zentralbl Chir. 2013;138(5):575-581. German [with English abstract].

16. Zeller T, Frank U, Bürgelin K, et al. Early experience with a rotational thrombectomy device for treatment of acute and subacute infra-aortic arterial occlusions. J Endovasc Ther. 2003;10(2):322-331.

17. Wissgott C, Kamusella P, Richter A, Klein-Weigel P, Schink T, Steinkamp HJ. [Treatment of acute femoropopliteal bypass graft occlusion: comparison of mechanical rotational thrombectomy with ultrasound-enhanced lysis]. Rofo. 2008;180(6):547-552. German [with English abstract].
18. Bérczi V, Deutschmann HA, Schedlbauer P, Tauss J, Hausegger KA. Early experience and midterm follow-up results with a new, rotational thrombectomy catheter. Cardiovasc Intervent Radiol. 2002;25(4): 275-281.

19. Antonov AV, Schmidt T, Wang Y, Mewes HW. ProfCom: a web tool for profiling the complex functionality of gene groups identified from high-throughput data. Nucleic Acids Res. 2008;36(Web Server Issue): W347-W351.

20. Stanek F, Ouhrabkova R, Prochazka D. Mechanical thrombectomy using the Rotarex catheter-safe and effective method in the treatment of peripheral arterial thromboembolic occlusions. Vasa. 2010;39(4): 334-340. 


\section{Supplementary materials}
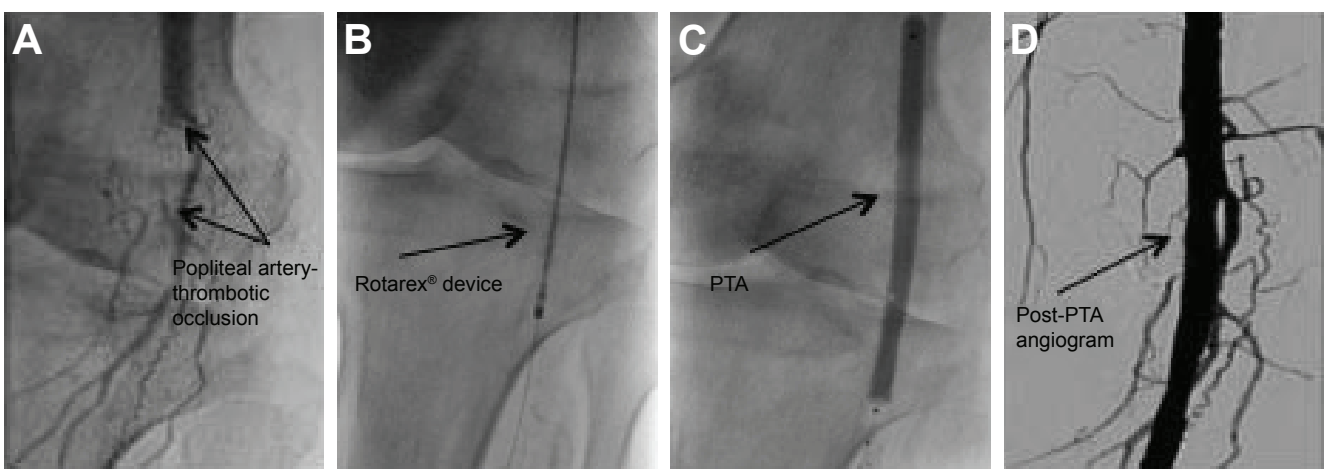

Figure SI A typical example of an acute thrombotic occlusion of the popliteal artery (A), insertion and advancement of the Rotarex ${ }^{\circledR}$ device (B), PTA (C), and final revascularization angiogram following the successful mechanical thrombectomy (D).

Abbreviation: PTA, percutaneous transluminal angioplasty.
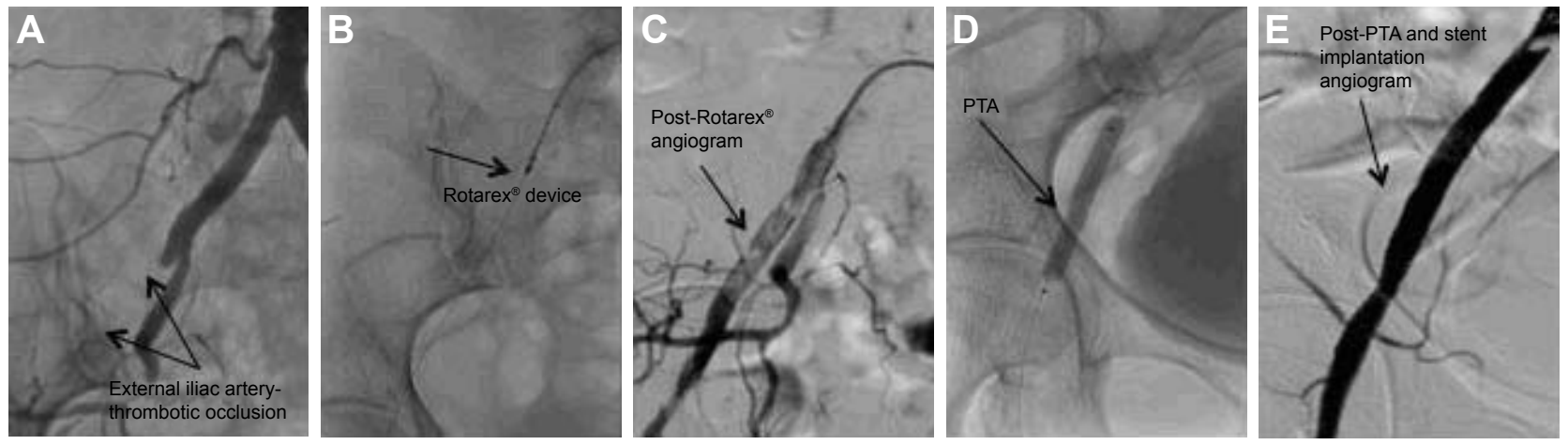

Figure S2 An example of acute thrombotic occlusion of the external iliac artery (A), insertion and advancement of the Rotarex ${ }^{\circledR}$ device (B), intermediate result (C), PTA (D), as well as revascularization angiogram following the successful mechanical thrombectomy/PTA/stent implantation (E).

Abbreviation: PTA, percutaneous transluminal angioplasty.

Table SI Number of patients where ABI had been determined

\begin{tabular}{|c|c|c|c|c|c|c|}
\hline ABI & $\begin{array}{l}\text { Pre (prior to } \\
\text { intervention) }\end{array}$ & $\begin{array}{l}\text { Post (post- } \\
\text { intervention) }\end{array}$ & I month & 3 months & 6 months & 12 months \\
\hline Rotarex $^{\circledR}$ & 95 & 105 & 46 & 49 & 40 & 33 \\
\hline Lysis & 15 & 15 & 6 & 9 & 7 & 8 \\
\hline Rotarex ${ }^{\circledR}+$ lysis & 16 & 17 & 9 & 8 & 6 & 5 \\
\hline
\end{tabular}

Abbreviation: $\mathrm{ABI}$, ankle-brachial index.

\section{Publish your work in this journal}

Drug Design, Development and Therapy is an international, peerreviewed open-access journal that spans the spectrum of drug design and development through to clinical applications. Clinical outcomes, patient safety, and programs for the development and effective, safe, and sustained use of medicines are the features of the journal, which

\section{Dovepress}

has also been accepted for indexing on PubMed Central. The manuscript management system is completely online and includes a very quick and fair peer-review system, which is all easy to use. Visit http://www.dovepress.com/testimonials.php to read real quotes from published authors.

Submit your manuscript here: http://www.dovepress.com/drug-design-development-and-therapy-journal 